\title{
Capnocytophaga canimorsus: A Human Pathogen Feeding at the Surface of Epithelial Cells and Phagocytes
}

\author{
Manuela Mally ${ }^{19}$, Hwain Shin ${ }^{19}$, Cécile Paroz ${ }^{1}$, Regine Landmann ${ }^{2}$, Guy R. Cornelis ${ }^{1 *}$
}

1 Infection Biology, Biozentrum, University of Basel, Klingelbergstrasse, Basel, Switzerland, 2 Infection Biology, Department of Research, University Hospital Basel, Hebelstrasse, Basel, Switzerland

\begin{abstract}
Capnocytophaga canimorsus, a commensal bacterium of the canine oral flora, has been repeatedly isolated since 1976 from severe human infections transmitted by dog bites. Here, we show that $C$. canimorsus exhibits robust growth when it is in direct contact with mammalian cells, including phagocytes. This property was found to be dependent on a surface-exposed sialidase allowing C. canimorsus to utilize internal aminosugars of glycan chains from host cell glycoproteins. Although sialidase probably evolved to sustain commensalism, by releasing carbohydrates from mucosal surfaces, it also contributed to bacterial persistence in a murine infection model: the wild type, but not the sialidase-deficient mutant, grew and persisted, both when infected singly or in competition. This study reveals an example of pathogenic bacteria feeding on mammalian cells, including phagocytes by deglycosylation of host glycans, and it illustrates how the adaptation of a commensal to its ecological niche in the host, here the dog's oral cavity, contributes to being a potential pathogen.
\end{abstract}

Citation: Mally M, Shin H, Paroz C, Landmann R, Cornelis GR (2008) Capnocytophaga canimorsus: A Human Pathogen Feeding at the Surface of Epithelial Cells and Phagocytes. PLoS Pathog 4(9): e1000164. doi:10.1371/journal.ppat.1000164

Editor: Ambrose Cheung, Dartmouth Medical School, United States of America

Received May 21, 2008; Accepted August 27, 2008; Published September 26, 2008

Copyright: (c) 2008 Mally et al. This is an open-access article distributed under the terms of the Creative Commons Attribution License, which permits unrestricted use, distribution, and reproduction in any medium, provided the original author and source are credited.

Funding: This work was funded by Swiss National Science Foundation grant Nr 32-65393.01.

Competing Interests: The authors have declared that no competing interests exist.

* E-mail: guy.cornelis@unibas.ch

9 These authors contributed equally to this work.

\section{Introduction}

Capnocytophaga canimorsus (formerly Centers for Disease Control group DF-2) has been rarely but regularly isolated from dog or cat bite infections since its discovery in 1976 [1,2]. C. canimorsus is a thin Gram-negative rod, found in the normal oral flora of dogs and cats. Clinical infections by C. canimorsus generally appear as fulminant septicemia, peripheral gangrene or meningitis $[3,4]$. Splenectomy, alcohol abuse and immunosuppression have been associated with a number of cases, but more than $40 \%$ of the patients have no obvious risk factor [5]. Capnocytophaga belongs to the family of Flavobacteriaceae in the phylum of Bacteroidetes, which is taxonomically remote from Proteobacteria. The family of Bacteroidaceae contains many commensals of the mammalian intestinal system such as Bacteroides thetaiotaomicron and Bacteroides fragilis [6]. The family of Flavobacteriaceae includes a variety of environmental and marine bacteria, among which Flavobacterium johnsoniae is a common soil and freshwater bacterium studied for its gliding motility [7]. There are only a few examples of pathogenic bacteria belonging to this family. These are Flavobacterium psychrophilum, the causative agent of cold water disease in salmonid fish [8], Ornithobacterium rhinotracheale, a bacterial pathogen known for causing respiratory disease in poultry [9], and Riemerella anatipestifer which causes "duckling disease" in waterfowl and turkeys $[10,11]$. The genus Capnocytophaga includes seven species found in normal human oral flora and $C$. canimorsus found in the normal flora of dogs and cats. More than 160 cases of $C$. canimorsus infections have been reported so far [12] but very few studies have addressed the molecular mechanisms of $C$. canimorsus pathogenesis. Recently, we showed that $C$. canimorsus 5 (Cc5) resists phagocytosis by macrophage cell line $[13,14]$. We also showed that although $C$. canimorsus does not affect the viability of murine or human macrophages, it does not elicit proinflammatory cytokines and it even blocks the proinflammatory response to the LPS from enterobacteria [13]. In the course of such experiments, Cc5 exhibited robust growth, although it is usually considered fastidious for growth. In the present study, we show that a surface-localized sialidase plays a key role in initiating an extensive deglycosylation process of host cell glycan structures and that this feeding mechanism serves as a basis for growth and persistence of C. canimorsus in vivo.

\section{Results}

Growth of C. canimorsus 5 requires direct contact with cells

When inoculated at a multiplicity of infection (moi) of 20 to J774.1 murine macrophages cultured in complete RPMI (cRPMI), which includes $10 \%$ fetal bovine serum (FBS), Cc5 multiplied about 100-fold during the $24 \mathrm{~h}$ of infection (Fig. 1A). This observation could be repeated with non-phagocytic human epithelial HeLa cells and with canine epithelial MDCK kidney cells (Fig. 1B). Surprisingly, growth was abolished when J774.1 macrophages were omitted and moreover, $C c 5$ was unable to grow in a transwell system, indicating that direct contact is required for bacterial growth (Fig. 1B). This implies that Cc5 may take advantage of some nutrient that is present on the host cell surface. Notably, Cc5 did not adhere tightly to cells and was not internalized (data not shown). We generated a transposon ( $\mathrm{Tn}$ ) mutant library using Tn 4351 from $B$. fragilis $[15,16]$ and isolated a 


\section{Author Summary}

Capnocytophaga canimorsus is a commensal bacterium of dogs/cats oral flora, which causes rare but severe infections in humans that have been bitten or simply licked by a dog/cat. Fulminant septicemia and peripheral gangrene are most common symptoms. Although splenectomy has been identified as a predisposing factor, some $40 \%$ of the patients have no immunosuppression history. C. canimorsus belongs to the phylum Bacteroidetes, which includes many commensals of the human gut flora but few pathogens. C. canimorsus has been shown previously to be immunosuppressive and to resist phagocytosis by macrophages. Here, we show that this bacterium feeds on surface-exposed glycoproteins from cultured mammalian cells. This property, which was found to depend on a bacterial surface-exposed sialidase, suggests that in its natural niche-the dog's oral cavity- $C$. canimorsus may feed on the dog's mucosal cells. Moreover, we found that $C$. canimorsus also feeds on phagocytes and that sialidase contributes to persistence and virulence in a mouse infection model. Thus, by adapting to its ecological niche, $C$. canimorsus also developed the potential to persist within the tissues of an infected host. This observation nicely illustrates how commensalism and pathogenesis are two faces of the same coin.

clone that was unable to grow in the presence of J774.1 cells, but grew normally on blood agar plates. Wild type (wt) and mutant bacteria grew equally well in serum enriched heart infusion medium (Fig. 1C). Impaired growth of this Tn mutant was not due to an increased phagocytic uptake by J774.1 since addition of cytochalasin D had little effect on bacterial growth (Fig. 1B).
Surface-localized sialidase is required for the growth of Cc5 in contact with cells

The transposon inserted at codon 77 within a gene encoding a protein with similarity to bacterial sialidase, glycosylhydrolase that cleaves terminal sialic acid from glycoconjugates (Fig. 2A). The mutated gene, designated siaC, was found to be located downstream of genes encoding a predicted transcriptional regulator and a putative $\mathrm{N}$-acyl-glucosamine epimerase (accession number: EU329392). The first gene downstream was found to start $148 \mathrm{bp}$ further from the siaC stop codon (Fig. 2B). To exclude any polar effects of the Tn integration, we tested whether the downstream gene was transcriptionally linked to siaC. Total RNA was isolated from wt $C c 5$, reverse transcribed using two different primers annealing either at the end of siaC (5132) or at the end of the downstream gene (5129) and the cDNA was amplified by PCR. As shown in Fig 2C, even though transcripts were present for both genes separately, no transcript spanned sia $C$ and the downstream gene. This result indicates that sia $C$ is not transcriptionally linked to the downstream gene.

While intact $C c 5$ bacteria cleaved 2'-(4-Methylumbelliferyl)- $\alpha$ D-N-acetylneuraminic acid (MUAN), the Tn mutant could not, indicating that the mutated gene does indeed encode a sialidase (Fig. 3A). We engineered an expression shuttle vector by taking advantage of a cryptic plasmid isolated from another strain of $C$. canimorsus and the promoter of an insertion sequence from $B$. fragilis [16]. We constructed plasmids encoding full length (FL) SiaC, a variant deprived of the $21 \mathrm{~N}$-terminal residues, predicted to be a signal peptide $(\Delta 1-21)$, and a catalytic mutant (Y488C). Sialidase activity (Fig. 3A) and growth in the presence of J774.1 cells (Fig. 3B) was restored by introducing in trans sia $C_{\mathrm{FL}}$, but not sia $C_{\Delta 1-}$ 21. Sialidase activity was not restored to wt levels by sia $C_{\mathrm{Y} 488 \mathrm{C}}$, but it was still significant (Fig. 3A), suggesting that this residual activity might account for elevated growth in comparison to the siaC
A

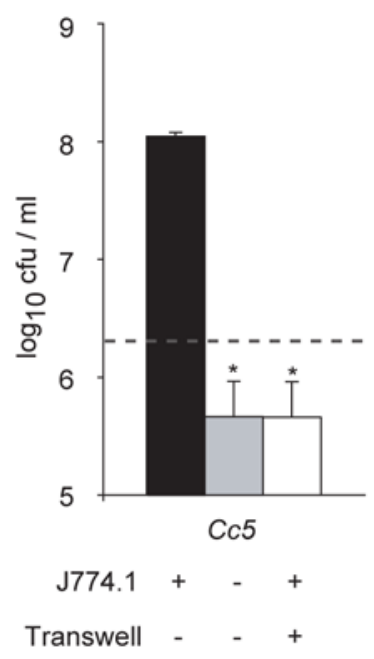

B
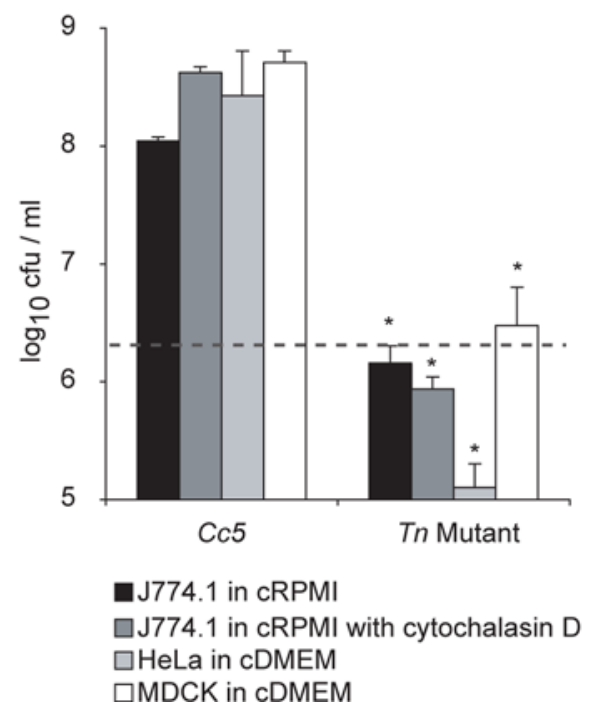

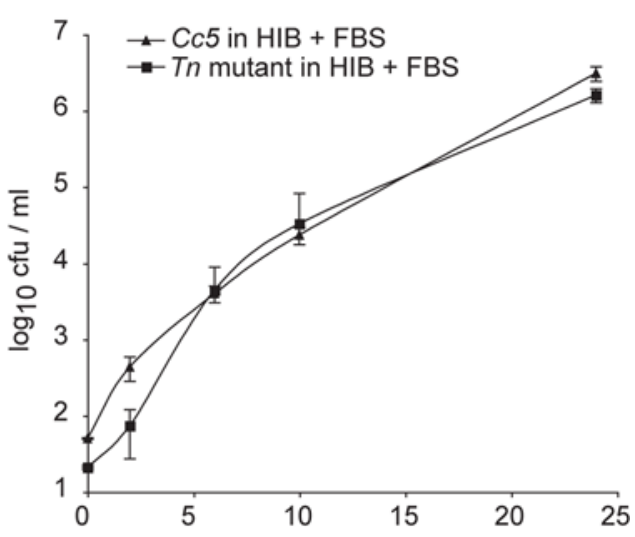

time (h)

Figure 1. Growth of $C$. canimorsus 5 is dependent on cell contact. (A) Viable counts of $2 \times 10^{6} \mathrm{Cc} 5$ after $24 \mathrm{~h}$ in presence of J774.1 macrophages in RPMI supplemented with $10 \%$ FBS ( $\mathrm{moi}=20)$ (black) or in RPMI with FBS without cells (grey) and in a transwell system preventing physical contact between bacteria and macrophages in RPMI with FBS (white). (B) Viable counts of $C c 5$ and Tn mutant after $24 \mathrm{~h}$ culture with macrophages in RPMI and FBS (black), with macrophages in RPMI and FBS in addition of cytochalasin D (grey), with HeLa cells (light grey) and MDCK cells in DMEM and FBS (white). The grey dotted line represents the bacterial number inoculated. The difference is statistically significant between $C c 5$ and Tn mutant (2tailed unpaired Student's t test $\mathrm{p}<0.05$ ) in 3 or more experiments. (C) Growth curve of wt Cc5 (triangles) and Tn mutant (squares) in heart infusion broth (HIB) supplemented with 10\% FBS, represented as the mean of 3 or more experiments with the error bars showing the s.d. doi:10.1371/journal.ppat.1000164.g001 
MNRIFYLLFA FVLLSACGSQ KNVIGGGEFT QPEMPLVTGK ENLLASFKLA TKNLNAITEV KVLLKSELKS LDLSEITIYL SDKENFKEAQ QFASTKSVQS TTLLKGNYLP KTENTYVWVT TKTTENPNLL NKIKVFQIEF LSNGSRYVYV NPKSASQRFG ITLRDKKQDG IECYRIPGLA TTNKGTLIAV YDNRYNNCKD LQEDVNVGMS RSTDGCOTWS PMKEIMDLGE WGGLDNRLNG IGDPAVLVDK TTGTIWVAAL WLHGHDKDKM AWWASKPGMT PHETGQLMIV KSEDDGTHWS FPINITAQTK DPKWYLFFNG PGSGITLNDG KIMFAAQYKD ENQVPHSTIT YSDDHGKTWH CGTGAKSHTT EAQVVQLSDG SIMLNMRDDR NRQNYTLSDA FHGRSVAVTR DFGKTWTEES TSRKALTEPN CMASIISLDK NGKKYLFFSN PADAKKRVNM TIKVSDDDGN_TWDKLPALKL YENEGFGYSC MSIIDDKYIG ILYEGAGDLI FQKIPVEEFI KN

B

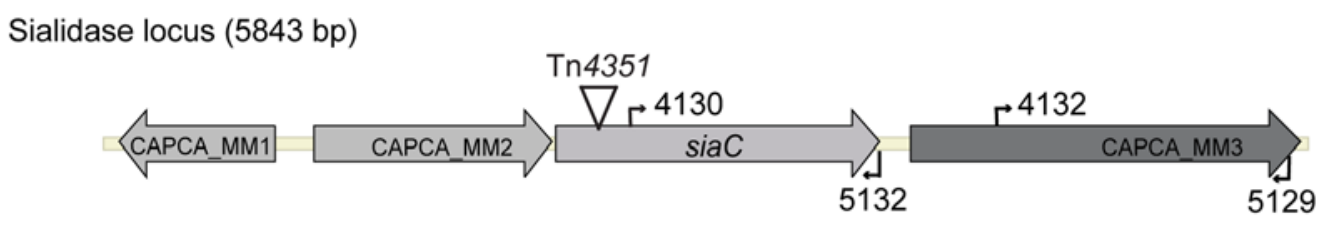

C

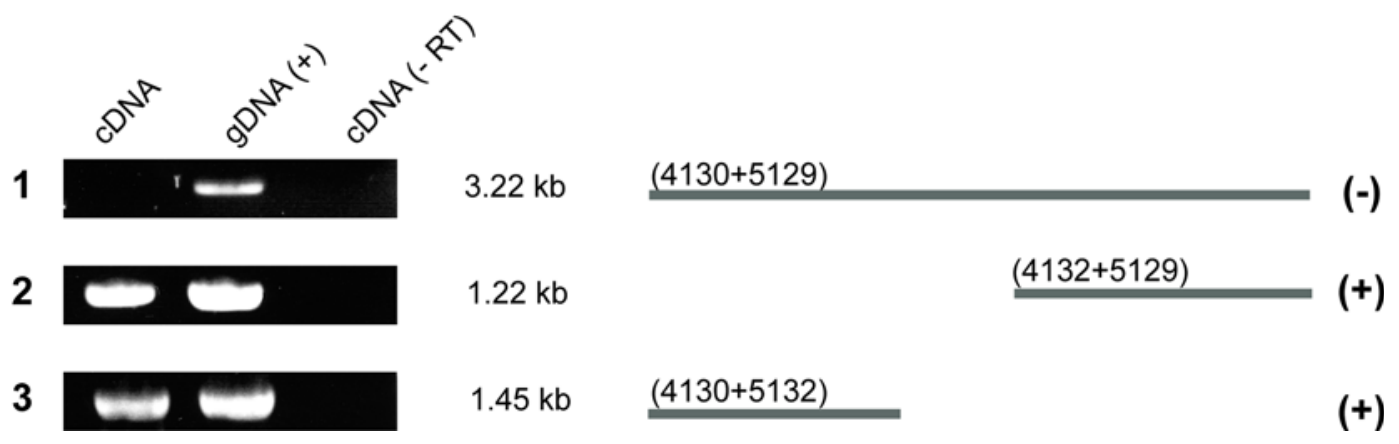

Figure 2. Identification of the Tn integration site and analysis of mRNA present in wt $C$. canimorsus 5. (A) Amino acid sequence of the $C$. canimorsus sialidase showing the signal peptide (italics) and the BNR/asp repeats (Ser/Thr-X-Asp-X-Gly-X-Thr-Trp/Phe) of bacterial sialidases (boxed). Domain predictions were analyzed by InterProScan [42]. The residues conserved in sialidases at the C-terminus are underlined and the tyrosine 488 is bold [43]. The Tn4351 integration site in SiaC at amino acid 77 is indicated, boxed in grey and bold. (B) Genetic locus of the sialidase gene (siaC) including its upstream genes, gntR-like gene (CAPCA_MM1) and putative $\mathrm{N}$-acyl-glucosamine epimerase encoding gene (CAPCA_MM2); and downstream coding sequence (CAPCA_MM3). (C) Reverse transcription performed on total RNA with specific primers (5129 or 5132) followed by PCR to identify transcripts present in wt C C5 (CDNA). PCR reactions were also performed using genomic DNA (gDNA) as template instead of CDNA as a positive control. As a control, reverse transcription was performed without reverse transcriptase in a parallel assay and used as template for the subsequent PCR reaction (-RT).

doi:10.1371/journal.ppat.1000164.g002

mutant (Fig. 3B). Using a sarcosyl extraction method, SiaC $\mathrm{FL}_{\mathrm{FL}}$ and $\mathrm{SiaC}_{\mathrm{Y} 488 \mathrm{C}}$ were found to be associated with the outer membrane (Fig. 3C), whereas $\mathrm{SiaC}_{\Delta 1-21}$ was only detected in total cells (Fig. 3B). Indirect immunofluorescence using polyclonal anti-SiaC serum on paraformaldehyde fixed but unpermeabilized bacteria confirmed that $\mathrm{SiaC}$ is exposed on the bacterial surface unless the signal peptide is removed (Fig. 3D). Although it is surface exposed, no SiaC could be detected in the supernatant of infected J774.1 cultures, indicating that it is tightly associated with the outer membrane (Fig. 3G). Hence, surface-localized sialidase is required for growth of $C c 5$ at the expense of mammalian cells.

Growth is sustained by N-acetyl glucosamine (GlcNAc) and $\mathrm{N}$-acetyl galactosamine (GalNAc) but not by sialic acids

Since sialidases cleave terminal sialic acid from glycoconjugates, we first tested whether the addition of sialic acids could restore growth of siaC. Addition of neither sialic acid (Neu5Ac, N-Acetyl2,3-dehydro-2-deoxyneuraminic acid) nor its activated form
(CMP-Neu5Ac, Cytidine-5'-monophospho-N-acetylneuraminic acid) restored growth of siaC in presence of J774.1. In contrast, growth could be restored by the addition of purified recombinant $\mathrm{SiaC}$ or neuraminidase/sialidase $\mathrm{NanH}$ from Clostridium perfringens to the culture medium, but not by the addition of the catalytically inactive $\mathrm{SiaC}_{\mathrm{Y} 488 \mathrm{C}}$ (Fig. 4A). This suggested that removal of terminal sialic acids from glycoconjugates is required to make other carbohydrates accessible. Indeed, $\mathrm{N}$-acetyl glucosamine (GlcNAc) and N-acetyl galactosamine (GalNAc), common carbohydrate moieties of glycoconjugates, allowed growth of sia $C$ in the presence of macrophages (Fig. 4B). Notably, addition of glucose (Glc), galactose (Gal), mannose (Man) or sialyl-lactose (Nacetylneuraminosyl-D-lactose) could not restore growth of siaC bacteria (Fig. 4C). As galactose ( $\mathrm{Gal}$ ) is a common sugar preceding GlcNAc in glycan molecules, we next tested addition of N-acetyl lactosamine (LacNAc), a disaccharide consisting of $\beta$-D-Gal $\beta(1 \rightarrow 4)$ GlcNAc. LacNAc also restored the growth defect of siaC indicating the presence of an active $\beta$-galactosidase releasing monosaccharides Gal and GlcNAc in wt and siaC Cc5 (Fig. 4B). 
A

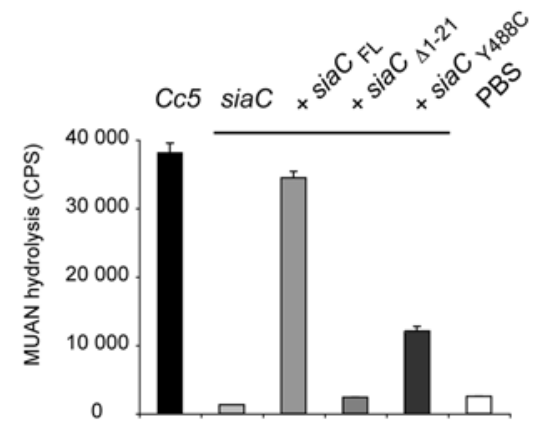

C

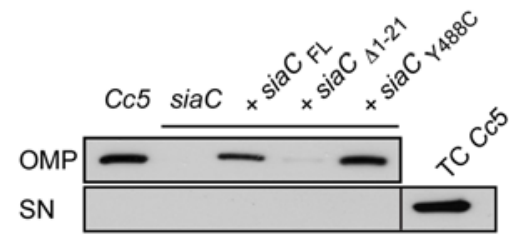

B

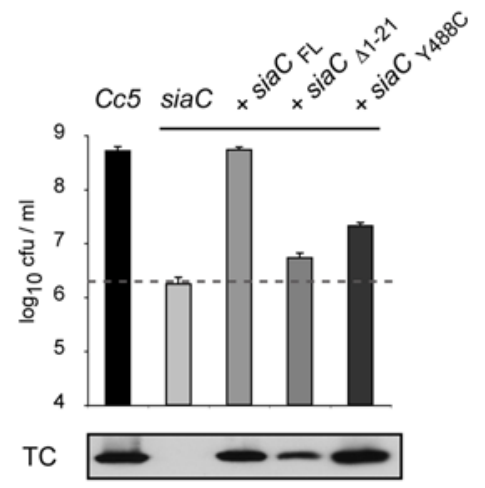

D

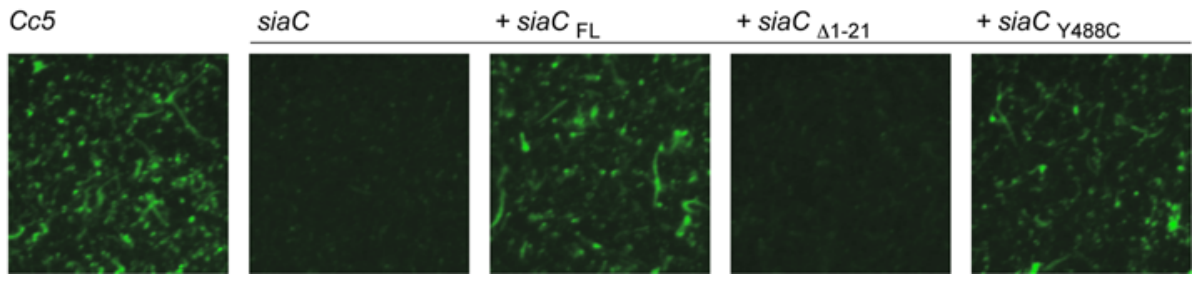

Figure 3. Surface localized sialidase is required for growth. (A) Sialidase activity of intact bacteria, measured with the substrate MUAN as the mean of triplicate measurements and s.d. of a representative experiment. (B) Viable counts after challenge with $2 \times 10^{6} \mathrm{Cc5}$ (black), siaC (light grey) or siaC complemented with plasmids containing sia $\mathrm{C}_{\mathrm{FL}}, \operatorname{sia}_{\Delta 1-21}$ and $s i a \mathrm{C}_{\mathrm{Y} 488 \mathrm{C}}$ after $24 \mathrm{~h}$ in presence of J774.1 with the grey dotted line indicating the bacterial number inoculated. Sialidase was detected by immunoblotting with a polyclonal antibody against SiaC in total cells (TC). (C) Outer membrane protein fractions (OMP), cell free supernatants (SN) of the J774.1 cultures shown in (B) including as control TC of Cc5 were analyzed by immunoblotting for the presence of SiaC. (D) Surface localization of SiaC was tested by immunofluorescence on paraformaldehyde fixed but not permeabilized bacteria using anti-SiaC followed by anti- rabbit IgG conjugated to FITC. doi:10.1371/journal.ppat.1000164.g003

\section{Sialidase desialylates macrophage and epithelial cell surfaces}

J774.1 macrophages were incubated with either wt or siaC bacteria and thereafter analyzed for lectin binding to investigate desialyation process on the macrophage cell surface. We used Sambucus nigra agglutinin (SNA), which recognizes terminal sialic acids (2- 6 or 2-3) linked to Gal or to GalNAc, and peanut agglutinin (PNA), a lectin specific for Gal ( $\beta$ 1-3) GalNAc, a disaccharide often forming the core unit of O-linked glycoconjugates (Fig. 5A). As shown in Fig. 5B, wt bacteria greatly reduced the amount of sialic acids (SNA panel) and Gal ( $\beta$ 1-3) GalNAc (PNA panel) at the cell surface, while sia $C$ bacteria had no effect on glycans masked by sialic acids. When cells were treated simultaneously with purified $\mathrm{SiaC}$ and siaC bacteria, neither sialic acid nor Gal ( $\beta 1-3)$ GalNAc were detected, indicating that siaC bacteria are still proficient in extensive deglycosylation of exposed glycans chains. The same deglycosylation of cell surfaces was observed when HeLa epithelial cells were used (Fig. 5C).

\section{Sialidase inhibitor N-Acetyl-2,3-dehydro-2-} deoxyneuraminic acid (Neu5Ac2en) can inhibit growth of Cc5

As bacterial and viral sialidases can share common ASP boxes that interact with sialic acid, we postulated that common sialidase inhibitor might have sufficient specificity for the active site in SiaC to inhibit growth of $C c 5 \mathrm{wt}$ bacteria in presence of cells. We tested the anhydro sialate derivative Neu5Ac2en, which is known to inhibit many viral and bacterial neuraminidases [17,18]. Approximately $150 \mathrm{cfu} / \mathrm{ml}$ of wt $C c 5$ were inoculated to a culture of J774.1 macrophages in the presence of $1 \mathrm{mM}$ Neu5Ac2en and growth was monitored after 2, 6, 10 and 24 h (Fig. 6A). Between 2 and $24 \mathrm{~h}$ post infection, counts of wt Cc5 were significantly reduced to values close to the siaC mutant (Fig. 6B). These data indicate that Neu5Ac2en has affinity for the active site of SiaC and restricts the growth of $C c 5$ in the presence of J774.1 cells.

\section{Cc5 but not siaC is able to persist in murine tissue cages}

To test whether sialidase could play a role during $C$. canimorsus systemic infection, we selected a murine tissue cage infection model [19]. Around $10^{7} \mathrm{cfu}$ of wt or siaC Cc5 bacteria were injected directly into Teflon cages, which had been subcutaneously implanted in C57BL/6 mice. Colony forming units (cfu) counts of wt decreased on day 2 and 5. However, on day 9 they increased by 1 to 3 logs in 4 out of 5 mice, and were able to persist in 3 of 5 mice after 27 days post infection with more than $10^{7}$ bacteria per $\mathrm{ml}$ fluid. The $s i a C$ bacteria were undetectable after the second day in 5 out of 5 infected mice (Fig. 7A). After infection, the total number of leukocytes in tissue cage fluid $\left(1.8 \times 10^{4}+/-1.3 \times 10^{4}\right.$ leukocytes $/ \mu \mathrm{l}$, mean $+/-$ standard deviation, s.d.) did not 
A

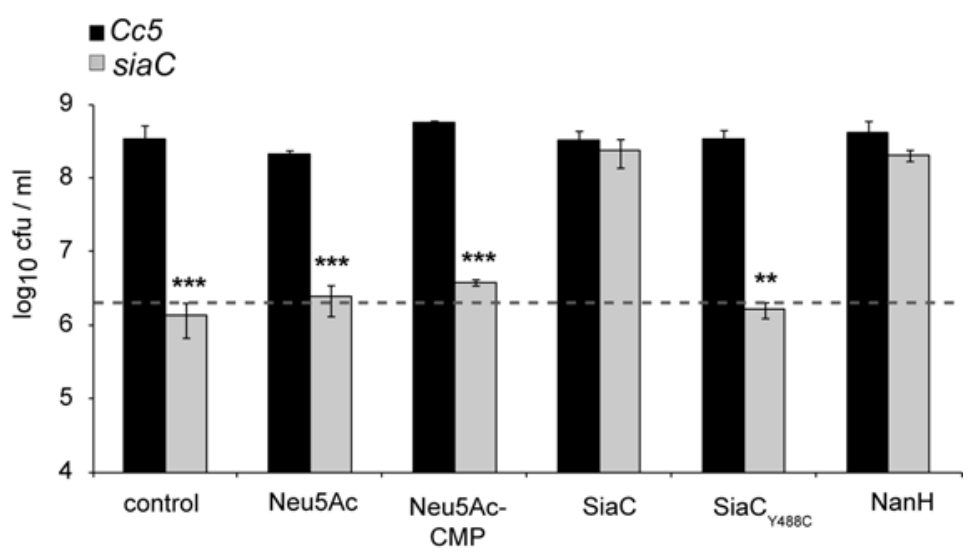

B

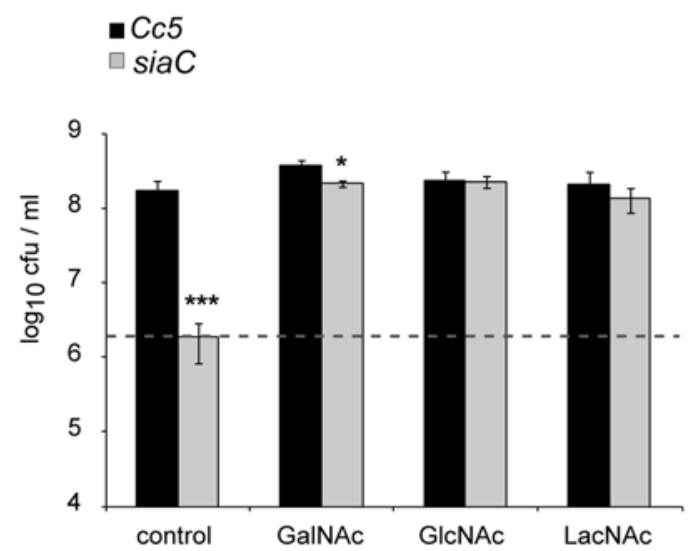

C

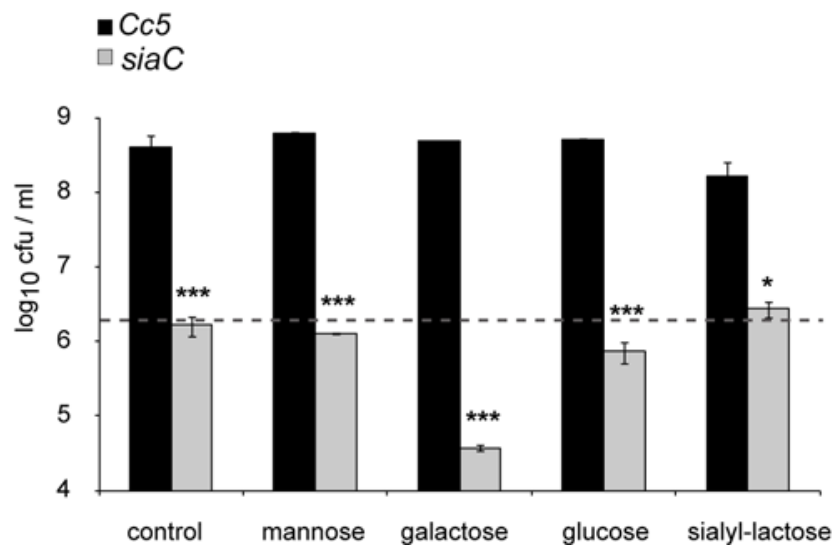

Figure 4. Aminosugars but not sialic acids sustain growth of $C$. canimorsus. Viable counts after challenge with $2 \times 10^{6}$ wt $C c 5$ (black) or siaC (grey) grown for $24 \mathrm{~h}$ with J774.1 in CRPMI (control) or in the same condition with the addition of Neu5Ac, Neu5Ac- CMP, $12.5 \mathrm{ng} / \mathrm{ml}$ enzyme SiaC $\mathrm{FL}$, $\mathrm{SiaC}_{\mathrm{Y} 488 \mathrm{C}}$ or NanH from C. perfringens (A) or with the addition of GalNAc, GlcNAc or LacNAc (B) or with the addition of mannose, galactose, glucose or sialyl-lactose (C). Mean values from 3 or more experiments and s.d. are shown including statistical difference between wt $C c 5$ and siaC with * $\mathrm{p}<0.05$, ${ }^{* *} p<0.01$ and ${ }^{* * *} p<0.001$ for each pair of columns (2-tailed unpaired Student's $t$ test). The grey dotted line indicates the bacterial number inoculated.

doi:10.1371/journal.ppat.1000164.g004

significantly increase and was not related to the bacterial load, suggesting that Cc5 infection did not lead to strong leukocyte recruitment. This was in agreement with the suppression of inflammation, which we previously reported [13]. In mixed infections, the competitive index of sia $C$ bacteria was $9.7 \times 10^{-4}$, $5.8 \times 10^{-7}$ and $4.7 \times 10^{-7}$ on day 5,9 and 14 , respectively. As 
A
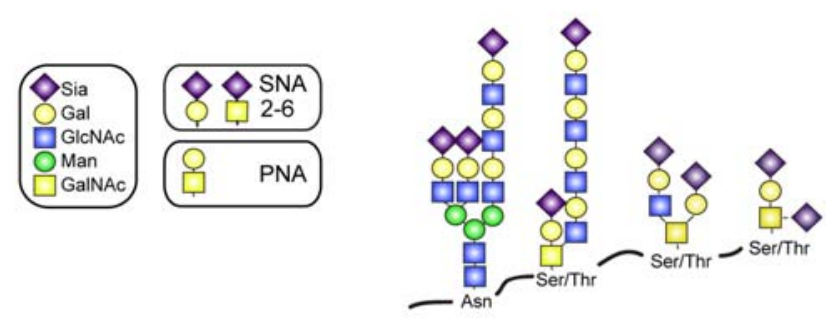

B

J774.1 2 h p.i. with moi $400\left(4 \times 10^{7}\right.$ bacteria/ml)
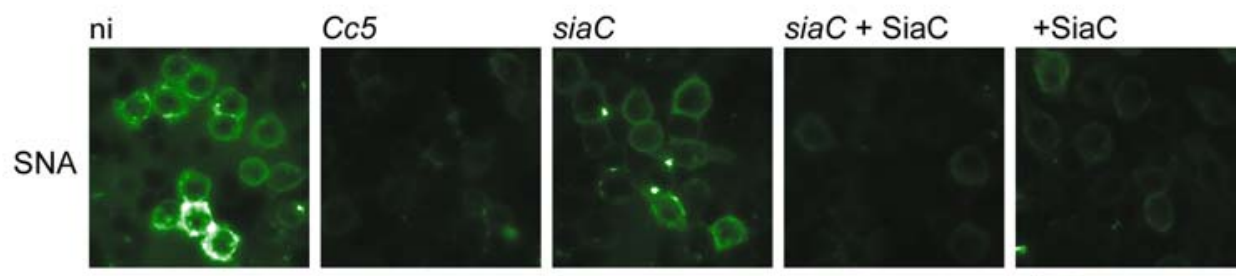

PNA
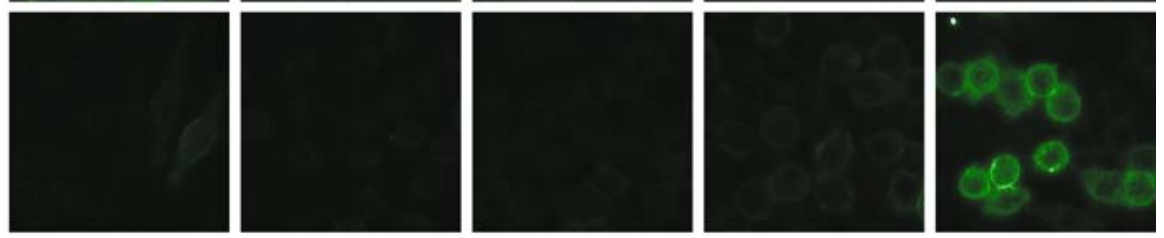

C

HeLa 2 h p.i. with moi $400\left(4 \times 10^{7}\right.$ bacteria/ml $)$
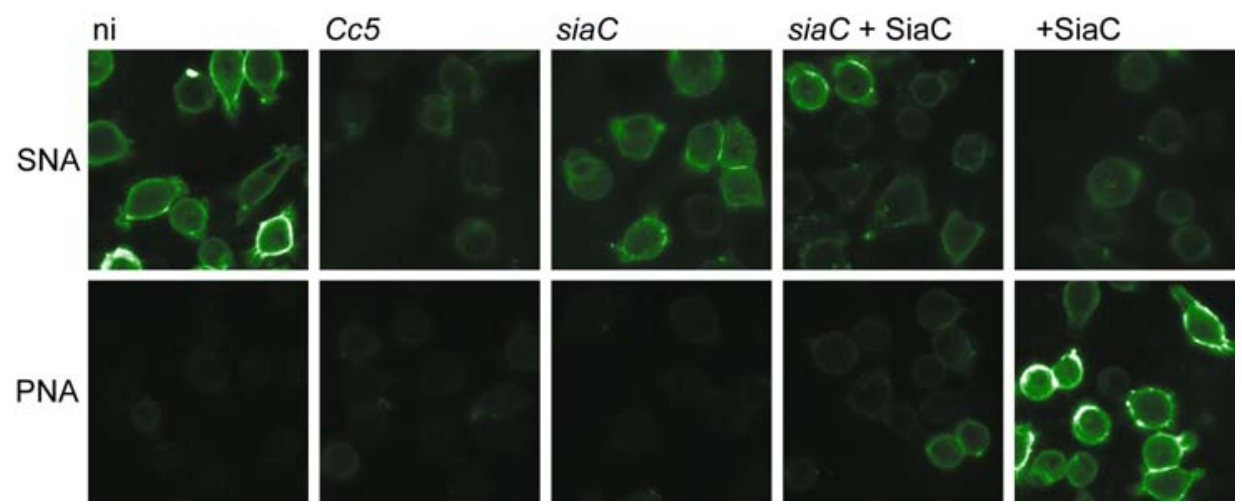

Figure 5. C. canimorsus desialylates macrophage and epithelial cell surfaces. (A) The targets of the lectins used in this study are schematically represented (adapted from [44]). Surface carbohydrates of J774.1 macrophages (B) or HeLa epithelial cells (C) were analyzed by lectin binding after $2 \mathrm{~h}$ of infection with $4 \times 10^{7} \mathrm{wt}(\mathrm{Cc} 5)$ or siaC bacteria. Cells were fixed with paraformaldehyde and incubated for $1 \mathrm{~h}$ with lectin SNA, which recognizes terminal sialic acids (2- 6 or 2-3) linked to Gal or to GalNAc or PNA that binds to the disaccharide Gal 1-3 GalNAc only after removal of terminal sialic acids. SiaC was added to cells alone or with siaC bacteria at $100 \mathrm{ng} / \mathrm{ml}$. Biotinylated lectins were visualized by FITC conjugated streptavidin.

doi:10.1371/journal.ppat.1000164.g005

observed during infection with wt $C c 5$ alone, 3 mice out of 5 that were infected by both strains developed a persistent infection (Fig. 7B).

The fluid from uninfected control cages was collected and the leukocytes and liquid were tested separately for their capacity to sustain growth of $C c 5$. Interestingly, wt $C c 5$ did not grow in the presence of the cell-free liquid (data not shown) but they grew in presence of leukocytes whereas siaC bacteria did not (Fig. 7G). Both strains grew equally well in heart infusion broth supple- mented with 10\% FBS, indicating a similar fitness in vitro (Fig. 1C). Mixed cultures in heart infusion broth supplemented with $10 \%$ FBS showed comparable growth of wt and siaC bacteria. Both strains reached $10^{6} \mathrm{cfu} / \mathrm{ml}$ after $24 \mathrm{~h}$ (Fig. 7D).

Our data from mixed infection in mice suggest that there is no cross-feeding of nutrients between wt and siaC Cc5 (Fig. 7B). We thus tested whether there would be cross-feeding between wt and siaC bacteria when inoculated to J774.1 cultures. When wt and sia $C$ were inoculated together at 1:1 ratio to J774.1 cells, wt Cc5 
A

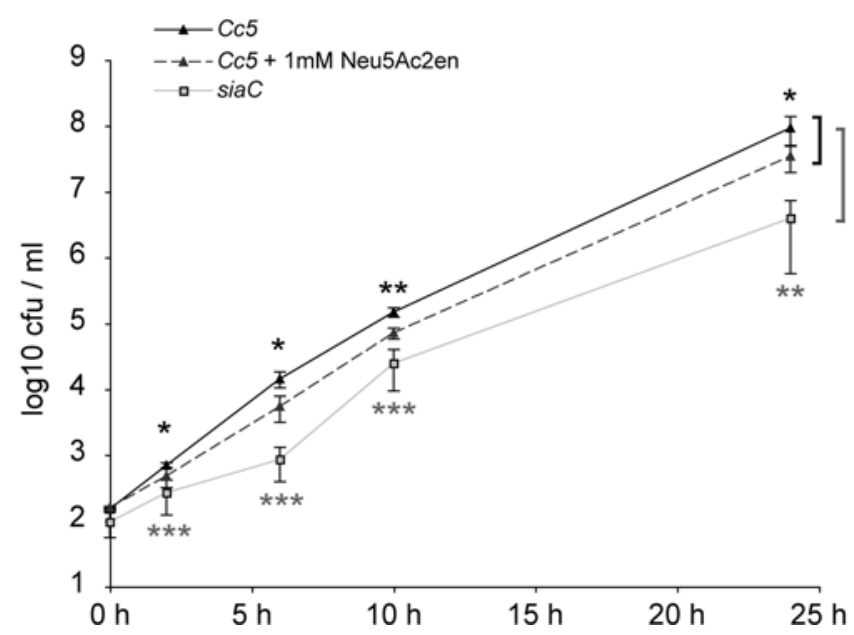

B

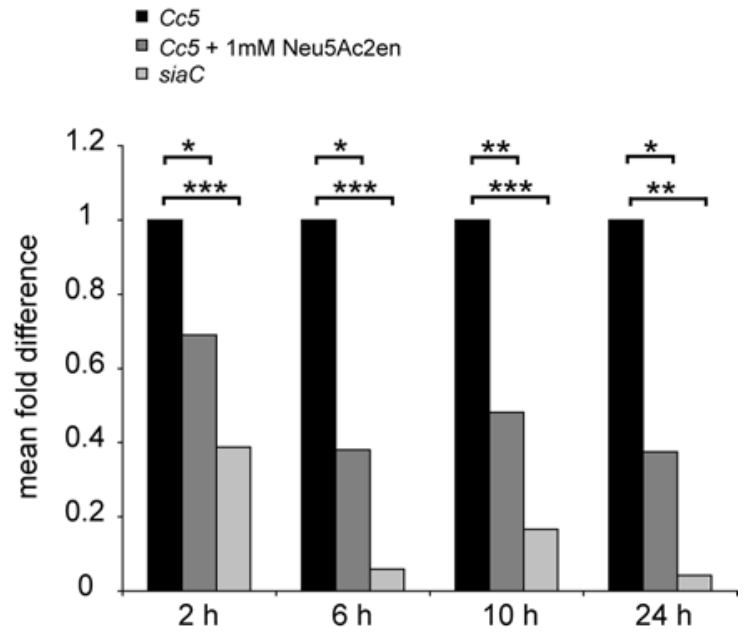

Figure 6. The sialidase inhibitor Neu5Ac2en decreases growth of wt $C$. canimorsus 5 in presence of macrophages. (A) Viable counts of approximately 150 bacteria grown in CRPMI in the presence of J774.1 cells for 2, 6, 10 and $24 \mathrm{~h}$ : siaC bacteria (light grey); wt Cc5 bacteria with $1 \mathrm{mM}$ Neu5Ac2en (grey, dotted line); wt Cc5 in the absence of inhibitor (black). Mean values from 4 experiments and s.d. are shown including statistical difference between $C \subset 5$ and siaC in grey or between $C \subset 5$ and $C c 5$ treated with Neu5Ac2en in black with * $p<0.05$, ${ }^{* *} p<0.01$ and ${ }^{* * *} p<0.001(2-$ tailed unpaired Student's $t$ test). (B) Data from viable counts (mean) shown in (A) is represented as the fold difference compared to wt Cc5. The statistical difference is depicted from (a) with ${ }^{*} p<0.05,{ }^{* *} p<0.01$ and ${ }^{* * *} p<0.001$

doi:10.1371/journal.ppat.1000164.g006

reached $10^{8} \mathrm{cfu} / \mathrm{ml}$ while siaC bacteria only reached $3 \times 10^{6} \mathrm{cfu} /$ $\mathrm{ml} 24 \mathrm{~h}$ post infection (Fig. 7E).

Taken together, these results demonstrate that SiaC plays an essential role in allowing persistence of wt Cc5 in this tissue cage model and that clearance of siaC bacteria is not due to a growth defect per se but to an altered interaction of the mutant with the host. Since sialidase is surface-exposed, one could consider the possibility that it alters the susceptibility to complement. Hence, we checked the susceptibility of wt and siaC Cc5 to mouse complement and found no difference (data not shown). It is also very unlikely that $s i a C$ bacteria have an increased sensitivity to killing by mouse leukocytes. Indeed, we tested phagocytosis and killing by human polymorphonuclear leukocytes and found no difference between wt and siaC bacteria (Manuscript in preparation). Hence, we conclude that the role of sialidase in infected mice is essentially nutritional.

\section{Discussion}

Sialic acids are a family of nine carbon acid sugars among which Neu5Ac is one of the most widespread variants. Sialic acids are predominantly found at the terminal position of cell-surface and secreted eukaryotic glycan structures and are involved in many physiological processes including binding to microbes and downregulation of innate immunity [20-22]. Therefore it is not surprising that sialic acids play a role in a variety of host microbe interactions. Several pathogens have evolved ways to expose sialic acid on their surface and hence to escape complement killing and opsonization by mimicry. Sialic acids are incorporated into capsules by E. coli K1 [23], Group B Streptococci [24], Serogroups B, C, W135 and Y Neisseria meningitidis [25]. The lipooligosaccharide of Neisseria gonorrhoeae, Neisseria meningitidis and Haemophilus influenzae are also sialylated [26]. In this case, a bacterial sialyltransferase uses CMP-Neu5Ac from the host as a substrate [26]. Sialic acids can also be synthesized from lactate by Neisseria itself, demonstrating a close link between metabolism and evasion of innate immune defenses [27].
Besides molecular mimicry, many microbes can utilize sialic acids as a source of carbon and nitrogen like E. coli K1, $H$. influenzae or C. perfringens [28]. Their metabolism comprises a permease for uptake and a neuraminiate lyase for conversion to $\mathrm{N}$ acetyl mannosamine, which is either degraded or used in sialic acid biosynthesis. A number of commensal and pathogenic bacteria are also endowed with a sialidase, a glycosylhydrolase that cleaves sialic acid from sialo-glycoconjugates. Bacterial sialidases have been thought since a long time to contribute to virulence in bacteria that colonize mucosal surfaces such as Vibrio cholerae, Streptococcus pneumoniae, group B streptococci, C. perfringens and $B$. fragilis but the exact role of sialidase on virulence remains controversial [29]. Recently, it was shown that a sialidase is involved in the formation of Pseudomonas aeruginosa biofilms and hence contributes to colonization of the lungs during the initial stages of infection in cystic fibrosis patients [30]. In S. pneumoniae, a sialidase initiates an extensive deglycosylation of different host proteins, including IgAl and human secretory component [31]. Furthermore, the sequential action of exoglycosidases sustains growth of $S$. pneumoniae on human $\alpha-1$ acid glycoprotein, though growth is not as robust as on sucrose and lactose. Although the genetic analysis suggests that sugars from the glycan chain would sustain growth, this has not been shown directly [32].

In the present study, which is among the very first on the pathogenesis mechanisms of C. canimorsus, we demonstrate that a sialidase allows $C$. canimorsus to feed on glycan chains from glycoproteins. The role of sialidase is not to supply sialic acid since growth of the sialidase-deficient mutant could not be restored by adding sialic acid to the culture medium. Thus, we have a situation similar to that of $S$. pneumoniae: the role of sialidase is to provide access to masked sugars of surface-exposed glycoproteins. Growth of the sialidase-deficient mutant could be restored by amino sugars like GalNAc, GlcNAc and LacNAc but not by glucose, galactose, mannose or sialyl-lactose, indicating that the nutritional requirements of C. canimorsus are very different from those of $S$. pneumoniae.

Our study thus confirms the importance of a sialidase to initiate a deglycosylation process for bacterial metabolism. Moreover, in 
A

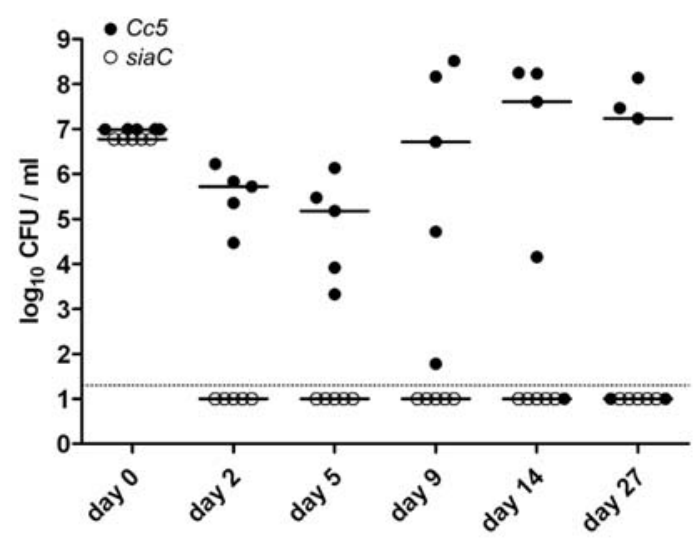

B

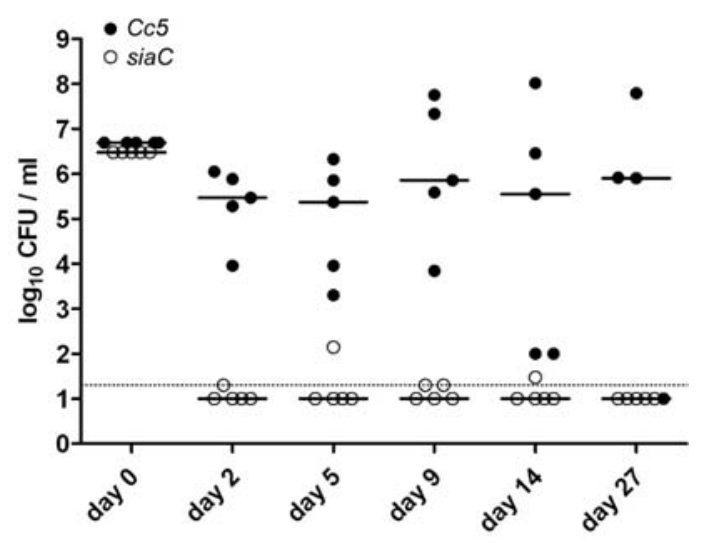

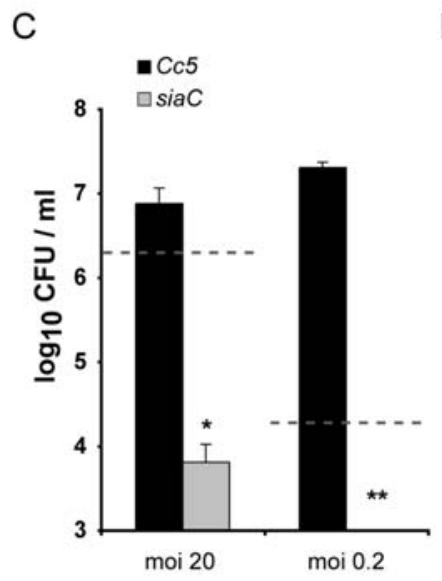
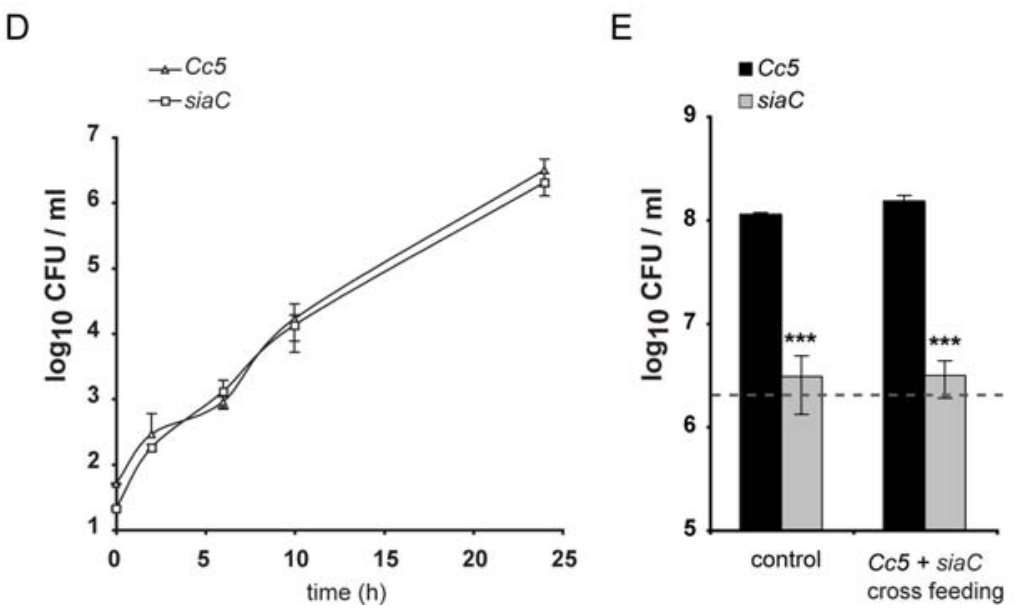

Figure 7. The sialidase mutant is hypo-virulent in a tissue cage mouse infection model. Tissue cages were implanted in C57BL/6 mice and infected with $10^{7} \mathrm{Cc} 5$ wt and siaC bacteria $(n=5)$ singly (A) or in competition (B). Bacteria were counted in tissue cage fluid (TCF) during 27 days $(C c 5=$ black circles; sia $C=$ open circles). Individual values are shown; horizontal lines indicate the median value of each group. The black dotted line is the detection limit of 20 bacteria per ml TCF. (A) Cfu numbers between groups were significantly different on days 2,5 and 9 with $p<0.01$ and on days 14 and 27 with $p<0.05$ (Mann Whitney test). (B) $10^{7} \mathrm{cfu} C \mathrm{C} 5$ and erythromycin resistant siaC were inoculated at a 1:1 ratio. Bacterial numbers were analyzed for 27 days $(n=5)$. Viable counts between wt and siaC were significantly different on day 2,5 and 9 with $p<0.01$ and on day 14 with $\mathrm{p}<0.05$. (C) Ex vivo isolated leukocytes were resuspended in serum free RPMI and inoculated at a moi of $20\left(2 \times 10^{6}\right.$ bacteria) or $0.2\left(2 \times 10^{4}\right.$ bacteria) indicated with grey dotted lines and bacterial viable count was monitored after $24 \mathrm{~h}$. Values represent the mean using TCF cells from 3 uninfected mice. TCF leukocytes consist of $68 \%+/-4.8 \%$ polymorphonuclear neutrophils (PMNs), $18 \%+/-3.2 \%$ monocytes and $9.1 \%+/-3.7 \%$ macrophages. $\mathrm{Wt}$ and siaC numbers were significantly different with $\mathrm{p}<0.05\left({ }^{*}\right)$ and $\mathrm{p}<0.001(* *)$ using 2-tailed unpaired student's $\mathrm{t}$ test. (D) In vitro, Cc5 and siaC were tested in heart infusion broth with FBS inoculated at a 1:1 ratio with approximately 100 bacteria total and bacterial growth was monitored for 2 , 6, 10 and $24 \mathrm{~h}$. (E) Viable counts after challenge with $2 \times 10^{6}$ (grey dotted line) CC5 (black) or siaC (grey) grown for $24 \mathrm{~h}$ with J774.1 in cRPMI singly (control) or at a 1:1 ratio (cross-feeding).

doi:10.1371/journal.ppat.1000164.g007

comparison with S. pneumoniae, C. canimorsus uses sialidase to feed on glycoproteins exposed at the surface of epithelial cells or even of macrophages, in spite of the fact that they do not adhere to these cells. The observation of extracellular bacteria specifically feeding on the surface of epithelial cells is not unprecedented. It has been described for B. thetaiotaomicron, a major commensal from the intestine, which feeds on fucosylated intestinal cells. Colonization by $B$. thetaiotaomicron even triggers the appearance of fucosyltransferase and fucosylated glycan expression [33]. Recent studies showed that host acquired fucose is incorporated by $B$. fragilis into capsular polysaccharide or glycoproteins, which in turn provides a survival advantage in the mammalian intestinal ecosystem [34]. As for C. canimorsus, it is likely that the capacity to feed on HeLa cells reflects the adaptation to feed on buccal epithelial cells.
Sialidase, which is pivotal in this feeding process, is surface localized and this surface localization is a prerequisite for unmasking glycan structures. It is not common to find enzymes anchored into the outer membrane, facing the outside of Gramnegative bacteria but there are examples like pullulanase a 116kDa isoamylase of Klebsiella oxytoca [35]. Not surprisingly, SiaC is endowed with an $\mathrm{N}$-terminal signal sequence, which turned out to be critical for its targeting. Sialidase thus crosses the cytoplasmic membrane via the Sec pathway but we have at present no explanation on how it crosses the outer membrane and remains anchored. It is probably not by a C. canimorsus specific mechanism since sialidase appeared to be also surface-exposed when expressed in E. coli (unpublished data). Sialidase could be a lipoprotein, like pullulanase. Alternatively, sialidase could be a surface-anchored 
auto-transporter protein like the $Y$. enterocolitica YadA [36]. However, the fact that the C-terminus of sialidase is not involved in the surface localization (unpublished data) argues against this hypothesis. Work in progress tries to address the question of how sialidase is anchored in the outer membrane.

Unlike what is observed with pullulanase, our data indicate that extremely little sialidase is released from $C$. canimorsus. This observation is in perfect agreement with the fact that $C$. canimorsus needs to be in direct contact with cells to feed on them. It also makes sense in the context of the mouth commensal microflora. Indeed, the oral cavity is occupied by some 500 different bacterial strains $[37,38]$, creating a fierce competition for nutrition. The fact that $C$. canimorsus does not release this enzyme suggests that $C$. canimorsus maximizes the benefit of sialidase by not sharing this fitness factor with competing bacteria. In agreement with this hypothesis, there is no cross-feeding when wt and siaC Cc5 bacteria are inoculated together in the presence of macrophages. This implies that wt $C$. canimorsus must be extremely efficient in capturing the aminosugars that it extracts from the surface of cells and we hypothesize that $C$. canimorsus has dedicated high affinity transporters for these in its outer membrane.

Extracellular C. canimorsus replicated very efficiently not only when they were in direct contact with HeLa cells but also with J774.1 macrophages. Thus, C. canimorsus not only resists phagocytosis by cultured macrophages [13,14], but they even take advantage of macrophages whose normal function is to engulf and kill microbes. To our knowledge, this is the very first report of a pathogen that can feed on phagocytic cells. This observation suggests that sialidase could contribute to virulence. We used a mouse tissue cage model in which the readout is bacterial persistence and we observed a dramatic difference in persistence between wt and sialidase-deficient $C$. canimorsus. Even more, we gained evidence that in vivo, C. canimorsus also feeds on phagocytes. These observations confirm our hypothesis that sialidase contributes to virulence, at least in the mouse model. It seems reasonable to extrapolate that it also plays a critical role during human infections. We would however be reluctant to call sialidase a virulence factor since it most probably evolved as a fitness factor for commensalism in the dog's mouth. Nevertheless, the mouse experiment shows that it may become a persistence factor if $C$. canimorsus is introduced in the tissues from another host. Our study thus shows once again the link between metabolism and virulence, as already well documented in studies on Salmonella [39], Listeria [40] and Neisseria [27]. However, unlike what was seen with Salmonella, there seem to be no or very little redundancy in the in vivo metabolism of $C$. canimorsus since the loss of sialidase had dramatic consequences on growth. It is interesting to observe that nutrition in vivo may be quite specific in spite of a very rich nutritional environment. Indeed, only GlcNAc and GalNAc could rescue growth while glucose had no effect and galactose was even deleterious. This difference could result from the fact that unlike Salmonella, C. canimorsus is a commensal highly adapted to its niche and only exceptionally a pathogen. Specialization is probably the hallmark of a bacterium that is primarily a commensal and only rarely a pathogen. Finally, C. canimorsus represents one more example illustrating that the distinction between commensals and pathogens is illusive. Commensalism and pathogenesis are two faces of the same coin.

Influenza neuraminidases have been successfully targeted with chemotherapeutic inhibitors for prophylaxis and treatment [41]. Given the wide prevalence and important role of sialidases in microbial infections, inhibition of bacterial sialidases could also provide a mechanism to prevent bacterial spreading during infections. Here, we observed a significant inhibition of the growth of C. canimorsus in the presence of macrophages by Neu5Ac2en. These preliminary data indicate that microbial sialidases could indeed serve as an attractive drug target to prevent bacterial dissemination.

\section{Materials and Methods}

\section{Bacterial strains and growth conditions}

C. canimorsus 5 was routinely grown on Heart Infusion Agar (HIA; Difco) supplemented with 5\% sheep blood (Oxoid) for 2 days at $37^{\circ} \mathrm{C}$ in presence of $5 \% \mathrm{CO}_{2}$. Bacteria were harvested by gently scraping colonies off the agar surface, washed and resuspended in PBS. C. canimorsus was also grown in Heart Infusion Broth (Difco) supplemented with 10\% (v/v) fetal bovine serum (FBS; Invitrogen) for approximately $24 \mathrm{~h}$ without shaking in an $37^{\circ} \mathrm{C}$ incubator with $5 \% \mathrm{CO}_{2}$. Selective agents were added at the following concentrations: erythromycin, $10 \mu \mathrm{g} / \mathrm{ml}$; cefoxitin, $10 \mu \mathrm{g} / \mathrm{ml}$; gentamicin, $20 \mu \mathrm{g} / \mathrm{ml}$; ampicillin, $100 \mu \mathrm{g} / \mathrm{ml}$.

\section{Cell Culture and Infection}

Murine monocyte-macrophage J774A.1 cells (ATCG TIB-67) were cultured in RPMI 1640 (Invitrogen) supplemented with 10\% (v/v) FBS (Invitrogen), $2 \mathrm{mM}$ L-glutamine and $1 \mathrm{mM}$ sodium pyruvate. Human epithelial HeLa cells (ATCG CGL-2) and canine epithelial MDCK kidney cells (ATCG CCL-34) were grown in DMEM (Invitrogen) with 10\% (v/v) FBS. Cells were seeded in medium without antibiotics at a density of $10^{5} / \mathrm{cm}^{2}$ and cultured at $37^{\circ} \mathrm{C}$ in humidified atmosphere containing $5 \% \mathrm{CO}_{2}$. Unless otherwise indicated, infection was performed after $15 \mathrm{~h}$ at a moi of 20 representing $2 \times 10^{6}$ bacteria per $\mathrm{ml}$ in each well at $37^{\circ} \mathrm{C}$.

Monosaccharides and disaccharides (Sigma Aldrich) were added to $0.1 \%(\mathrm{w} / \mathrm{v})$ final concentration. Neu5Ac and CMPNeu5Ac were added to $0.01 \%$ final concentration.

Cc5 was pretreated with $1 \mathrm{mM} \mathrm{Neu} 5 \mathrm{Ac} 2 \mathrm{en}$ at $37^{\circ} \mathrm{C}$ for $30 \mathrm{~min}$. Subsequently, infection of $\mathrm{J} 774.1$ was carried out in presence of $1 \mathrm{mM}$ Neu5Ac2en during $24 \mathrm{~h}$.

\section{Arbitrarily Primed PCR}

Primers specific to the ends of the transposon and primers of random sequence that may anneal to chromosomal DNA sequences in close proximity to the transposon insertions were used in two rounds of PCR before sequencing. The first round of amplification was carried out in $50 \mu \mathrm{l}$ containing $100 \mathrm{ng}$ of genomic DNA, $1.5 \mathrm{mM} \mathrm{MgCl}_{2}, 200 \mu \mathrm{M}$ of primers 5' CAGAATTCTGTTGCATTTGCAAGTTG 3' complementary to Tn4351 and 5' ggccacgcgtcgactagtacNNNNNNNNNNacgcc3', $2.5 \mathrm{U}$ of DNA polymerase (DyNAzymeII, Finnzymes), $200 \mu \mathrm{M}$ of each dNTP, in $10 \mathrm{mM}$ Tris $\mathrm{HCl}\left(\mathrm{pH}\right.$ 8.3) for 6 cycles $\left(94^{\circ} \mathrm{C}\right.$ for $1 \mathrm{~min}, 30^{\circ} \mathrm{C}$ for $1 \mathrm{~min}, 72^{\circ} \mathrm{C}$ for $\left.2 \mathrm{~min}\right)$ and 30 cycles $\left(94^{\circ} \mathrm{C}\right.$ for $1 \mathrm{~min}, 45^{\circ} \mathrm{C}$ for $1 \mathrm{~min}, 72^{\circ} \mathrm{C}$ for $2 \mathrm{~min}$ ) and final $10 \mathrm{~min}$ at $72^{\circ} \mathrm{C}$. $10 \mu \mathrm{l}$ of PCR product containing random fragments was used as template in a second round of 30 cycles of amplification $\left(94^{\circ} \mathrm{C}\right.$ for $30 \mathrm{sec}, 45^{\circ} \mathrm{C}$ for $30 \mathrm{sec}, 72^{\circ} \mathrm{C}$ for $1 \mathrm{~min}$ ) using primers $5^{\prime}$ CAGAATTCTGTTGCATTTGCAAGTTG $3^{\prime}$ and $5^{\prime}$ GGCGACGGGTCGACTAGTAC $3^{\prime}$, from the $5^{\prime}$ of the random primer. PGR products were purified using NucleoSpin ${ }^{\circledR}$ from Machery Nagel. 20- $50 \mathrm{ng}$ of random sized products were sequenced using an ABI sequencer. The Tn integration site was further confirmed by using primers on chromosomal DNA by sequencing towards the Tn integration site. Primers used were $5^{\prime}$ AATTGTTGTAAGGATTGTCG $3^{\prime}$ or $5^{\prime}$ GCGAAGCGTTATCGCAAAGG $3^{\prime}$ complementary to the siaC sequence in a sequencing reaction containing $2 \mu \mathrm{g}$ genomic DNA of siaC, betaine $0.25 \mathrm{M}$ and BigDye Terminator Ready Reaction (PE 
Biosystems) with an initial denaturation step for $5 \mathrm{~min}$ and subsequent 99 cycles $\left(95^{\circ} \mathrm{C}\right.$ for $30 \mathrm{sec}, 50^{\circ} \mathrm{C}$ for $20 \mathrm{sec}, 60^{\circ} \mathrm{C}$ for $4 \mathrm{~min})$.

\section{RNA isolation and reverse transcription (RT) PCR}

Cc5 were grown for 2 days on HIA blood plates. RNA was isolated from $5 \times 10^{8}$ bacteria by a hot phenol/chloroform extraction method followed by DNase I (Amersham Pharmacia) treatment $(0.5 \mathrm{U} / \mu \mathrm{g} \mathrm{RNA})$ for $2 \mathrm{~h}$ at $37^{\circ} \mathrm{C}$. RNA was further cleaned by using a RNeasy kit (Quiagen) and stored at $-80^{\circ} \mathrm{C}$ until use. An additional DNase I digest was introduced with 0.25 $\mathrm{U} / \mu \mathrm{g}$ RNA for $15 \mathrm{~min}$ at $37^{\circ} \mathrm{C}$ and stopped by addition of final $2.5 \mathrm{mM}$ EDTA and heat inactivation at $75^{\circ} \mathrm{C}$ for $10 \mathrm{~min}$. Subsequent reverse transcription was performed with $50 \mathrm{U}$ Superscript II $/ \mu \mathrm{g}$ RNA in RT buffer (Invitrogen), $10 \mathrm{mM}$ DTT and $50 \mu \mathrm{M}$ specific primer (5129: 5' GGGTAATCGGCACTTGTCGGG3' or 5132: 5' GTTTAGTTCTTGATAAATTCG $3^{\prime}$ ) for $60 \mathrm{~min}$ at $42^{\circ} \mathrm{C}$ and stopped at $70^{\circ} \mathrm{C}$ for $10 \mathrm{~min} .10 \%$ of cDNA preparation or of a preparation made without addition of reverse transcriptase was subjected to PCR using following primer combinations: 4130 (5' GGGTAACAACAAAAACGACTG $\left.\quad 3^{\prime}\right)+5129 ; \quad 4132 \quad\left(5^{\prime} \quad\right.$ TATAAGAATAATTGGTGGGC $\left.3^{\prime}\right)+5129 ; 4130+5132$. $100 \mathrm{ng}$ of genomic DNA from $C c 5$ was used as a positive control of the PCR reactions.

\section{Construction of complementation and expression plasmids}

Full length siaC was amplified with 5' CATACGATGGGAAATCGAATTTTTTATCTT $3^{\prime}$ and $5^{\prime}$ GTTCTAGAGAGTTCTTGATAAATTCCTCAACTG $3^{\prime}$ primers and cloned into the E. coli- C. canimorsus shuttle vector pMM47.A [16] with $\mathcal{N} c o \mathrm{I}$ and $X b a \mathrm{I}$, leading to the insertion of a glycine at position 2 and a C- terminal histidine $6 \times$ tag in plasmid pMM52 $\left(\operatorname{sia}_{\mathrm{FL}}\right)$. Forward primer 5' AAAGCGATGGGAAACGTAATCGGGGGAGGGG $3^{\prime}$ was used with the same reverse primer to construct pMM50 (sia $\left.C_{\Delta 1-21}\right)$, deleting the first $63 \mathrm{bp}$ of sia $C$, but still including methionine and glycine at position 1 and 2 , respectively, and using a C-terminal His $6 \times$ tag. The catalytic mutation in siaC of was introduced by site directed mutagenesis with an inverse PCR on pMM52, using primers 5' GAAGGATTTGGGTGTTGGTGTATGTGG $3^{\prime}$ and 5' CGACATACACGAACACGCAAATCCTTC 3 ' leading to pMM59 (sia$\left.C_{\mathrm{Y} 488 \mathrm{C}}\right)$. Plasmids derived from pMM47.A contained the $c f x A$ gene originating from Bacteroides sp. and could be selected in C. canimorsus with $10 \mu \mathrm{g} / \mathrm{ml}$ cefoxitin [16]. The beta-lactamase also present on pMM47.A was used as a selection marker in E. coli.

The cDNAs encoding $\mathrm{SiaC}_{\Delta 1-21}$ (pHS2) were subsequently amplified using 5' GGAATTCGATATGAACGTAATCGGGGGAGGC $3^{\prime}$ plus 5' GGGGGATCGCTAGTTCTTGATAAATTCGTC $3^{\prime}$ and cloned into the expression vector pET15b(+) (Novagen). Plasmid pHS3 encoding SiaC $_{\Delta 1-21, Y 488 C}$ was constructed by site directed mutagenesis on template pHS2 using the same primers as described for pMM59. All constructs were sequenced with an ABI sequencer. The sequence of SiaC was deposited at GenBank (accession number: EU329392).

\section{Purification of recombinant $\mathrm{SiaC}$ and immunoblotting}

Expression of siaC constructs in E. coli BL21(DE3) was induced with $0.5 \mathrm{mM}$ isopropyl- $\beta$-D-1-thiogalactopyranoside at $\mathrm{A}_{600}=0.5$ for $3 \mathrm{~h}$. Proteins were purified by affinity chromatography using chelating Sepharose (Pharmacia) charged with $\mathrm{NiSO}_{4}$ according to the manufacturer's instructions. Samples were analyzed by
SDS-PAGE by the system of Laemmli, and immunoblotted. Polyclonal serum from rabbit was generated against recombinant $\mathrm{SiaC}_{\Delta 1-21}$. The antigen was injected at days $0,14,28$, and 56 with a final bleeding at day 80 (Laboratoire d'Hormonologie, Marloie, Belgium).

\section{MUAN hydrolysis}

$10^{7}$ bacteria were incubated with $0.006 \% 2^{\prime}$-(4-Methylumbelliferyl)- $\alpha$-D-N-acetylneuraminic acid (MUAN) in $0.25 \mathrm{M}$ sodium acetate $\mathrm{pH} 7.5$ at $37^{\circ} \mathrm{C}$ for $3 \mathrm{~min}$. Reactions were stopped with $50 \mathrm{mM} \mathrm{Na} 2 \mathrm{CO}_{3} \mathrm{pH} 9.6$ and fluorescence was determined at $445 \mathrm{~nm}$ with a Wallac Victor ${ }^{2} 1420$ Multilabel counter (Perkin Elmer).

\section{Outer Membrane Preparation}

Bacterial cells resuspended in PBS containing DNase and RNase $(10 \mu \mathrm{g} / \mathrm{ml})$, were sonicated on ice. Unbroken cells were removed at $3000 \times \mathrm{g}$ for $15 \mathrm{~min}$, and total membranes were collected at $20000 \times \mathrm{g}$ for $30 \mathrm{~min}$ at $4^{\circ} \mathrm{C}$. The membranes were suspended in PBS and sarcosyl (N-Lauroylsarcosine sodium salt, Sigma) was added to a final concentration of $1 \%$ (v/v). After incubation on ice for $1 \mathrm{~h}$, membranes were collected at $20000 \times g$ for $30 \mathrm{~min}$ and resuspended in electrophoresis sample buffer and analyzed by SDS-PAGE by the system of Laemmli.

\section{Immunofluorescence of bacteria}

$10^{7}$ bacteria were incubated on poly-D-lysine (BD) coated glass slides for $1 \mathrm{~h}$ at $37^{\circ} \mathrm{C}$ and subsequently fixed with $3 \%$ paraformaldehyde for $15 \mathrm{~min}$. Anti- SiaC polyclonal serum (1:500) and a FITC conjugated secondary antibody (Goat AntiRabbit IgG, Southern Biotech) was used at $1 \mu \mathrm{g} / \mathrm{ml}$ and fluorescence was measured with a Leica DMIRE2 microscope. Pictures were taken with a digital camera (Hamamatsu Photonics) and analyzed with OpenLab software (version 3.1.2) and Adobe Photoshop CS3 (version 10.0.1).

\section{Lectin Staining}

$10^{5} \mathrm{~J} 774.1$ macrophages or HeLa epithelial cells were seeded on poly-D-lysine coated slides. Infection was carried out with $4 \times 10^{7}$ bacteria for $2 \mathrm{~h}$. Uninfected cells were alternatively treated with purified recombinant $\mathrm{SiaC}$ at $100 \mathrm{ng} / \mathrm{ml}$. Cells were fixed with $3 \%$ paraformaldehyde for $15 \mathrm{~min}$. Biotinylated lectins SNA and PNA (Vector Laboratories) were incubated with cells at $2 \mu \mathrm{g} / \mathrm{ml}$ and $2.5 \mu \mathrm{g} / \mathrm{ml}$, respectively, for $1 \mathrm{~h}$. After washing with PBS, cells were treated with $1 \mu \mathrm{g} / \mathrm{ml}$ fluorescein conjugated streptavidin (Vector Laboratories) and fluorescence was determined on mounted slides (Vectashield, Vector Laboratories).

\section{Mice and tissue cage infection model}

12 week-old male C57BL/6 mice were maintained under pathogen-free conditions in the Animal Facility of the Department of Research, University Hospital Basel. Animal experiments were performed in accordance with the guidelines of the Swiss veterinary law. Teflon tissue cages were implanted subcutaneously in the back of anesthetized mice as previously described [19]. The cages consisted of closed Teflon cylinders $(10 \mathrm{~mm}$ diameter, $30 \mathrm{~mm}$ length, internal volume $1.84 \mathrm{ml}$ ) with 130 regularly spaced $0.2 \mathrm{~mm}$ holes. 2 weeks after surgery, $200 \mu \mathrm{l}$ of bacterial suspension was injected percutaneously into the cage. Prior to infection, sterility of the tissue cage was verified. Tissue cage fluid (TCF) was sampled at day 2, 5, 9, 14 and 27 and examined for leukocytes and bacterial viable counts. Leukocytes from TCF were quantified with a Coulter counter (Coulter Electronics) and 
differentiated by Diff-Quick (Medion Diagnostics) Wright staining of cytospins and examined under light microscopy. The percentage of viable leukocytes was assessed by trypan blue exclusion.

The survival of sia $C$ bacteria in the competition experiment was compared directly with wt Cc5 in individual animals giving a 1:1 ratio of wt to mutant bacteria. The number of mutant (erythromycin resistant) and wt bacteria recovered from the TCF of animals was established by plating to media with and without erythromycin. The competitive index was calculated as the (number of mutant/wild-type bacteria recovered from animals)/(number of mutant/wild-type bacteria in the inoculum).

\section{Statistical analysis}

For growth experiments, means and standard deviation (s.d.) were calculated and statistical significance was evaluated by using

\section{References}

1. Bobo RA, Newton EJ (1976) A previously undescribed gram-negative bacillus causing septicemia and meningitis. Am J Clin Pathol 65: 564-569.

2. Brenner DJ, Hollis DG, Fanning GR, Weaver RE (1989) Capnocytophaga canimorsus sp. nov. (formerly CDC group DF-2), a cause of septicemia following dog bite, and $C$. cynodegmi sp. nov., a cause of localized wound infection following dog bite. J Clin Microbiol 27: 231-235.

3. Pers C, Gahrn-Hansen B, Frederiksen W (1996) Capnocytophaga canimorsus septicemia in Denmark, 1982-1995: review of 39 cases. Clin Infect Dis 23: 71-75.

4. Le Moal G, Landron C, Grollier G, Robert R, Burucoa C (2003) Meningitis due to Capnocytophaga canimorsus after receipt of a dog bite: case report and review of the literature. Clin Infect Dis 36: e42-46.

5. Lion C, Escande F, Burdin JC (1996) Capnocytophaga canimorsus infections in human: review of the literature and cases report. Eur J Epidemiol 12: 521-533.

6. Coyne MJ, Comstock LE (2008) Niche-specific features of the intestinal bacteroidales. J Bacteriol 190: 736-742.

7. McBride MJ (2004) Cytophaga-flavobacterium gliding motility. J Mol Microbiol Biotechnol 7: 63-71.

8. Duchaud E, Boussaha M, Loux V, Bernardet JF, Michel C, et al. (2007) Complete genome sequence of the fish pathogen Flavobacterium psychrophilum. Nat Biotechnol 25: 763-769.

9. Schuijffel DF, van Empel PC, Pennings AM, van Putten JP, Nuijten PJ (2005) Successful selection of cross-protective vaccine candidates for Ornithobacterium rhinotracheale infection. Infect Immun 73: 6812-6821.

10. Segers P, Mannheim W, Vancanneyt M, De Brandt K, Hinz KH, et al. (1993) Riemerella anatipestifer gen. nov., comb. nov., the causative agent of septicemia anserum exsudativa, and its phylogenetic affiliation within the FlavobacteriumCytophaga rRNA homology group. Int J Syst Bacteriol 43: 768-776.

11. Subramaniam S, Huang B, Loh H, Kwang J, Tan HM, et al. (2000) Characterization of a predominant immunogenic outer membrane protein of Riemerella anatipestifer. Clin Diagn Lab Immunol 7: 168-174.

12. Tierney DM, Strauss LP, Sanchez JL (2006) Capnocytophaga canimorsus mycotic abdominal aortic aneurysm: why the mailman is afraid of dogs. J Clin Microbiol 44: 649-651.

13. Shin H, Mally M, Kuhn M, Paroz C, Cornelis GR (2007) Escape from immune surveillance by Capnocytophaga canimorsus. J Infect Dis 195: 375-386.

14. Meyer S, Shin H, Cornelis GR (2008) Capnocytophaga canimorsus resists phagocytosis by macrophages and blocks the ability of macrophages to kill other bacteria. Immunobiology: in press.

15. Cooper AJ, Kalinowski AP, Shoemaker NB, Salyers AA (1997) Construction and characterization of a Bacteroides thetaiotaomicron recA mutant: transfer of Bacteroides integrated conjugative elements is RecA independent. J Bacteriol 179: 6221-6227.

16. Mally M, Cornelis GR (2008) Genetic tools for Capnocytophaga canimorsus. Appl Environ Microbiol: in press.

17. Schreiner E, Zbiral E, Kleineidam RG, Schauer R (1991) 2,3-Didehydro-2deoxysialic acids structurally varied at $\mathrm{C}-5$ and their behaviour towards the sialidase from Vibrio cholerae. Carbohydr Res 216: 61-66.

18. Hoyer LL, Roggentin P, Schauer R, Vimr ER (1991) Purification and properties of cloned Salmonella typhimurium LT2 sialidase with virus-typical kinetic preference for sialyl alpha 2----3 linkages. J Biochem 110: 462-467.

19. Kristian SA, Lauth X, Nizet V, Goetz F, Neumeister B, et al. (2003) Alanylation of teichoic acids protects Staphylococcus aureus against Toll-like receptor 2dependent host defense in a mouse tissue cage infection model. J Infect Dis 188: $414-423$.

20. Schauer R (2000) Achievements and challenges of sialic acid research. Glycoconj J 17: 485-499.

21. Traving C, Schauer R (1998) Structure, function and metabolism of sialic acids. Cell Mol Life Sci 54: 1330-1349. a two- tailed, unpaired Student's $t$ test. Differences were determined to be significant when $\mathrm{p}<0.05$. For in vivo experiments, individual mouse values are shown including the median value of each group. Mann Whitney test with the post hoc Bonferroni correction was used for comparison between $C c 5$ and $\operatorname{sia} C \mathrm{cfu}$ numbers during infection.

\section{Acknowledgments}

We thank Z Rajacic, N Jann and M Schmaler for assistance during the in vivo studies.

\section{Author Contributions}

Conceived and designed the experiments: MM HS RL GRC. Performed the experiments: MM HS CP. Analyzed the data: MM HS RL GRC. Wrote the paper: MM HS RL GRC.

22. Varki NM, Varki A (2007) Diversity in cell surface sialic acid presentations: implications for biology and disease. Lab Invest 87: 851-857.

23. Barry GT (1959) Detection of sialic acid in various Escherichia coli strains and in other species of bacteria. Nature 183: 117-118.

24. Wessels MR, Rubens CE, Benedi VJ, Kasper DL (1989) Definition of a bacterial virulence factor: sialylation of the group B streptococcal capsule. Proc Natl Acad Sci U S A 86: 8983-8987.

25. Bhattacharjee AK, Jennings HJ, Kenny CP, Martin A, Smith IC (1975) Structural determination of the sialic acid polysaccharide antigens of Neisseria meningitidis serogroups $\mathrm{B}$ and $\mathrm{C}$ with carbon 13 nuclear magnetic resonance. J Biol Chem 250: 1926-1932.

26. Mandrell RE, Apicella MA (1993) Lipo-oligosaccharides (LOS) of mucosal pathogens: molecular mimicry and host-modification of LOS. Immunobiology 187: $382-402$.

27. Exley RM, Shaw J, Mowe E, Sun YH, West NP, et al. (2005) Available carbon source influences the resistance of Neisseria meningitidis against complement. J Exp Med 201: 1637-1645.

28. Vimr ER, Kalivoda KA, Deszo EL, Steenbergen SM (2004) Diversity of microbial sialic acid metabolism. Microbiol Mol Biol Rev 68: 132-153.

29. Corfield T (1992) Bacterial sialidases-roles in pathogenicity and nutrition. Glycobiology 2: 509-521.

30. Soong G, Muir A, Gomez MI, Waks J, Reddy B, et al. (2006) Bacterial neuraminidase facilitates mucosal infection by participating in biofilm production. J Clin Invest 116: 2297-2305.

31. King SJ, Hippe KR, Weiser JN (2006) Deglycosylation of human glycoconjugates by the sequential activities of exoglycosidases expressed by Streptococcus pneumoniae. Mol Microbiol 59: 961-974.

32. Burnaugh AM, Frantz LJ, King SJ (2007) Growth of Streptococcus pneumoniae on human glycoconjugates is dependent upon the sequential activity of bacterial exoglycosidases. J Bacteriol.

33. Bry L, Falk PG, Midtvedt T, Gordon JI (1996) A model of host-microbial interactions in an open mammalian ecosystem. Science 273: 1380-1383.

34. Coyne MJ, Reinap B, Lee MM, Comstock LE (2005) Human symbionts use a host-like pathway for surface fucosylation. Science 307: 1778-1781.

35. Pugsley AP, Kornacker MG, Ryter A (1990) Analysis of the subcellular location of pullulanase produced by Escherichia coli carrying the pulA gene from Klebsiella pneumoniae strain UNF5023. Mol Microbiol 4: 59-72.

36. Koretke KK, Szczesny P, Gruber M, Lupas AN (2006) Model structure of the prototypical non-fimbrial adhesin YadA of Yersinia enterocolitica. J Struct Biol 155: $154-161$.

37. Kroes I, Lepp PW, Relman DA (1999) Bacterial diversity within the human subgingival crevice. Proc Natl Acad Sci U S A 96: 14547-14552.

38. Paster BJ, Boches SK, Galvin JL, Ericson RE, Lau CN, et al. (2001) Bacterial diversity in human subgingival plaque. J Bacteriol 183: 3770-3783.

39. Becker D, Selbach M, Rollenhagen C, Ballmaier M, Meyer TF, et al. (2006) Robust Salmonella metabolism limits possibilities for new antimicrobials. Nature 440: 303-307.

40. Goetz M, Bubert A, Wang G, Chico-Calero I, Vazquez-Boland JA, et al. (2001) Microinjection and growth of bacteria in the cytosol of mammalian host cells. Proc Natl Acad Sci U S A 98: 12221-12226.

41. von Itzstein M (2007) The war against influenza: discovery and development of sialidase inhibitors. Nat Rev Drug Discov 6: 967-974.

42. Quevillon E, Silventoinen V, Pillai S, Harte N, Mulder N, et al. (2005) InterProScan: protein domains identifier. Nucleic Acids Res 33: W116-120.

43. Roggentin P, Rothe B, Kaper JB, Galen J, Lawrisuk L, et al. (1989) Conserved sequences in bacterial and viral sialidases. Glycoconj J 6: 349-353.

44. Varki A (2007) Glycan-based interactions involving vertebrate sialic-acidrecognizing proteins. Nature 446: 1023-1029. 